\title{
Type and Duration of Home Activities of Children with Specific Language Impairment: Case Control Study Based on Parents' Reports
}

\author{
Sinikka Hannus, ${ }^{1,2}$ Timo Kauppila, ${ }^{3}$ and Kaisa Launonen ${ }^{4}$ \\ ${ }^{1}$ Department of General Practice and Primary Health Care, Clinical Institute, HUCH, University of Helsinki, Helsinki, Finland \\ ${ }^{2}$ Vantaa Social Welfare and Health Care, Jönsaksentie 4, 01600 Vantaa, Finland \\ ${ }^{3}$ Department of General Practice and Primary Health Care, Clinical Institute, HUCH, University of Helsinki, \\ P.O. Box 20, 00014 Helsinki, Finland \\ ${ }^{4}$ Institute of Behavioural Sciences/Speech Sciences/Logopedics, University of Helsinki, P.O. Box 9, 00014 Helsinki, Finland
}

Correspondence should be addressed to Sinikka Hannus; sinikka.hannus@helsinki.fi

Received 9 April 2016; Revised 30 August 2016; Accepted 7 September 2016

Academic Editor: Olga Capirci

Copyright (c) 2016 Sinikka Hannus et al. This is an open access article distributed under the Creative Commons Attribution License, which permits unrestricted use, distribution, and reproduction in any medium, provided the original work is properly cited.

Parents of children with specific language impairment (SLI) are advised to promote language development at home. However, it is not known if children with SLI differ from healthy controls in their daily activities. This study collected prospectively information about the home activities of the children with SLI and their matched controls by using parents' daily reports. Participants were 20 matched pairs. The ages of children in matched pairs were from 6 to 8 years. During one week, parents filled in daily questionnaires of listed home activities. The observed time was between $5 \mathrm{pm}$ and $9.30 \mathrm{pm}$ each day and it was divided into 30 -minute scoring periods. Parents of children with SLI reported more varying home activities and fewer activities of playing outdoors than parents of control children. Home activities with literacy or screen time did not show difference between the two groups, and neither did playing table top games. Parents of children with SLI did more overlapping choices when scoring home activities than parents of control children. Children with SLI seemed to spend somewhat less time with home activities that, in particular, may ask for language and social skills and collaboration with peers.

\section{Introduction}

According to the International Classification of Diseases 10 (ICD10) [1], children with specific language impairment (SLI) can have diagnosis F80.1 or F80.2 [1]. Diagnosis F80.1 is an expressive language disorder in which the child's ability to use expressive spoken language is markedly below the appropriate level for the mental age, but in which language comprehension is within normal limits. There may or may not be abnormalities in articulation. Diagnosis F80.2 is a receptive language disorder in which the child's understanding of language is below the appropriate level for the mental age. In virtually all cases expressive language will also be markedly affected and abnormalities in word-sound production are common [1].
Among others, environmental factors have been suggested to explain the delayed language development as well as SLI of children $[2,3]$. Parents play a critical role in their children's language development, as they are the source of the genes and they modify the home environment of their children, thus, usually, facilitating and scaffolding the language development $[4,5]$. For example, one of the most important environmental factors affecting children's language skills has been suggested to be the quality of home literacy [6-8]. Significant relationship has been suggested between retrospectively reported home support for early literacy and performance on language tasks, even in adolescence [9]. However, studies of literacy experiences at home have often been carried out with retrospective questionnaires in which parents estimate the overall quantity of literacy experiences 
at home $[3,10,11]$. Analogously, increased use of media has been reported to induce putative harmful effects on young children's development in several studies among different cultures [12-15]. Because of the reports suggesting the negative effects of screen time on the development of a child the American Academy of Pediatrics (AAP) has even recommended limiting the daily screen time [16]. However, the possible differences of screen time have not been studied prospectively in children with and without SLI.

The effect of nature-nurture relationship on language development has been studied along many decades [17, 18] and, to support its significance, findings of empirical studies have suggested that collaborative work between parents and speech and language therapists (SLTs) benefits children's language development $[19,20]$. The focus of the intervention has turned from face-to-face with children settings to collaboration between parents and professionals [17, 19-21]. Furthermore, the International Classification of Functions (ICF) [22] calls for recognizing the environmental factors and considering them as part of intervention. This environmental intervention includes collaboration between parents and clinicians, because this collaboration and advising is supposed to have an effect also on the daily living of children that is expected to manifest itself as increased time spent at home on the recommended tasks and recommended daily activities. The quality of home literacy [6-8], activities like playing with peers and physical playing $[23,24]$, and use of media, especially television, [12-15] are just those putative daily activities which could be subjects of ecological intervention $[18,22]$ for children with SLI.

However, there is limited knowledge of the connections of language impairment on the daily activities of children with SLI, and these data are solely based on retrospective studies as stated before. Retrospective studies are prone to various biases [25]. To detect the putative differences in daily activities this study aimed at collecting information prospectively about the home activities of the children with SLI and their matched controls by using parents' daily reports. Our interest targeted the activities when children are at home with their parents.

\section{Materials and Methods}

2.1. Measurement of Activities at Home. Parent reports have been suggested to provide a valid access to parents' knowledge about their child across time and contexts and information about behavioural skills that are difficult to observe [2628 ]. Because of the absence of earlier studies of the daily basis questionnaires, the parent questionnaires in this study were first formulated according to the common knowledge and parent interviews of home activities of children in Finland. The second step was the pilot survey for parents outside of the aimed study groups that gave essential further knowledge of daily activities. The information of the pilot survey also conducted to the time scoring method used. Finally, the parents in this study filled in, during one week, daily questionnaires (see Appendix) where the observed time was between $5 \mathrm{pm}$ and $9.30 \mathrm{pm}$ each day and it was divided into
TABLE 1: Data of children with SLI in matched pairs: number of matched pairs in F80.1 and F80.2 and numbers of boys and girls.

\begin{tabular}{lccc}
\hline & Boys (\%) & Girls (\%) & Total (\%) \\
\hline F80.1 & $12(71 \%)$ & $2(67 \%)$ & $14(70 \%)$ \\
F80.2 & $5(29 \%)$ & $1(33 \%)$ & $6(30 \%)$ \\
Number of matched pairs & $17(100 \%)$ & $3(100 \%)$ & $20(100 \%)$ \\
& $(85 \%)$ & $(15 \%)$ & $(100 \%)$ \\
\hline
\end{tabular}

30 -minute scoring periods. As the children do not act in 30minute sessions, parents were advised to choose the main activity of their child in each particular session.

The four seasons are climatically very different in Finland and children's activities vary substantially according to the seasons. Therefore, the activities of all children were registered during the same week in April 2006.

2.2. Participants. This study is a part of a larger research SLI in Vantaa [29-31]. The research included all children born in 1998 and 1999 who were diagnosed in specialist health care in Helsinki University Central Hospital as having SLI (ICD10 diagnosis F80.1 or F80.2) living in the city of Vantaa, Finland. All of the diagnoses of the children in this study were specified in the specialist health care where guidelines and international definitions (DSM-V and ASHA) were in use. The size of this birth cohort was 4553 children in January 2006 [32]. Approximately one hundred children with SLI were found in the research data. The study criteria for the SLI group were the following: Finnish as mother language, normal intellectual ability, normal hearing, and diagnosis F80.1 or F80.2. For each case, a control child without the diagnosis of SLI was selected from the Vantaa population register. Furthermore, to ensure that also the parents of children with new diagnoses of SLI were informed of this study, the introductory letters were available in specialist health care units in the Helsinki University Central Hospital. The letter was accompanied by the preliminary letter of consent to be returned to the responsible researcher in a prepaid envelope. In the selection of control children, gender, month of birth $( \pm 1$ month), and the area of the town they lived in were matched. The matched case-control study design was chosen because it is the most efficient study design when outcomes are relatively rare, like SLI [33].

The flowchart of the child involvement in the study is given in Figure 1.

In the present study the parents of 56 children with SLI and 36 suggested control children accepted the study protocol. Parents of 38 (67.9\%) children with SLI and 30 (83\%) of matched control children returned the questionnaires. Out of the returned questionnaires the matched pairs run into each other in 20 pairs, for example, $53 \%$ of the returned questionnaires of children with SLI and $67 \%$ of the returned questionnaires of control children. The ages of children in matched pairs were as follows: six pairs, 6 years of age; ten pairs, 7 years of age; and four pairs, 8 years of age. Data of children with SLI in matched pairs are presented in Table 1. 


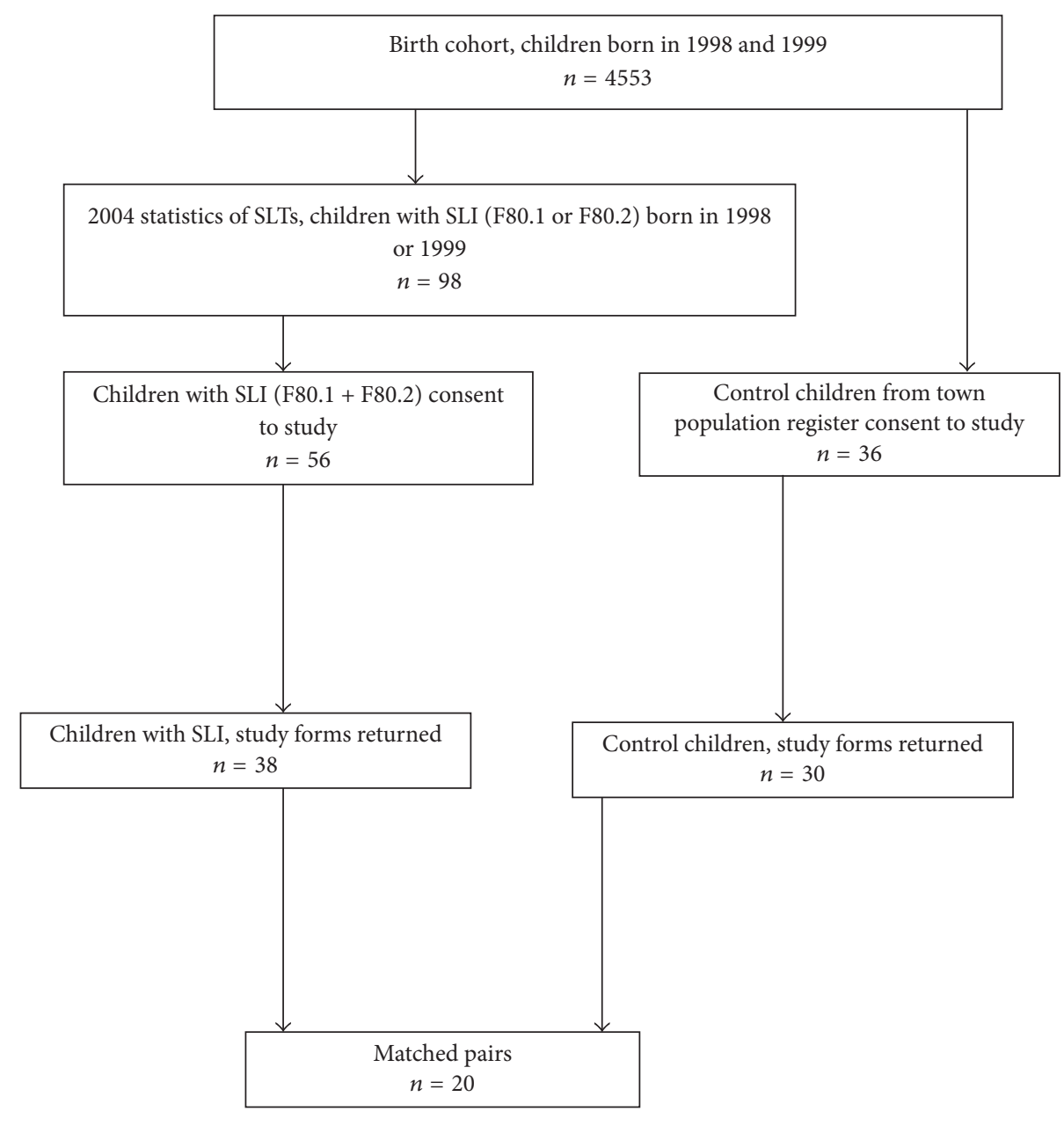

FIgURE 1: Flowchart of the study.

2.3. Data Analysis. The data were first analysed by counting together each child's activities separately for each day. Because the data suggested that during the weekends families had special activities when the questionnaires were not fulfilled, weekends were left out from the final analysis. Thus, the final data included the activities from Monday to Friday of the 20 matched pairs. Though parents were advised to select only one alternative for each 30-minute session, there were cases when parents selected more than one alternative. These overlapping choices caused different summarized follow-up times from Monday to Friday. To avoid false interpretations due to the overlapping choices, the second raw data processing was done in each activity that showed statistical significance. In order to test the strength of the putatively observed statistically significant differences of home activities the data was reanalysed by using the most unfavourable scores for each observed activity difference and thereby checking the specificity of the present findings [25, 34].

Cross tabulation was used to count the activities between each pair of children with SLI and their matched controls. The Chi-square test was used to analyse the difference in activities at home. Nonparametric test for related samples (Wilcoxon signed-rank test) was used to compare the children with SLI and their matched controls. The statistical difference level was $p=0.05$. PASW 18 was used to analyse the data.

\section{Results}

The preliminary analysis suggested that children with SLI played less outdoors (Figure 2), played less table top games $(p=0.05)$ (Table 2), and changed more activities (Figure 3$)$ than their typically developing controls. In the specificity testing the difference remained statistically significant in activities "playing outdoors" ( $p=0.03)$ and "changing activity" $(p=0.03)$ but in activity "playing table top games" (Table 2) it disappeared $(p=0.08)$.

In all other studied activities (playing indoors, building, drawing, looking at books, playing electric games, listening to reading, exercise at home indoors, watching TV/video, activities with music, guided hobbies, meal times, washing, sauna, and doing homework) the differences between the studied groups were not statistically significant (Table 2).

Parents in the two groups had made more than one choice for some 30-minute sessions. However, parents of children with SLI had made these overlapping choices statistically 
TABLE 2: Home activities with nonsignificant statistical difference. Median, $25 \%$ quartile, $75 \%$ quartile, and $p$ (signed-rank test) are presented.

\begin{tabular}{|c|c|c|c|c|c|}
\hline Activity & Group & Median (h) & $25 \%$ quartile & $75 \%$ quartile & $p$ \\
\hline \multirow{2}{*}{ Playing indoors } & SLI & 2.00 & 0.50 & 3,50 & \multirow{2}{*}{0.42} \\
\hline & Control & 1.50 & 0.50 & 2.40 & \\
\hline \multirow{2}{*}{ Building } & SLI & 0.00 & 0.00 & 1.00 & \multirow{2}{*}{0.92} \\
\hline & Control & 0.00 & 0.00 & 1.00 & \\
\hline \multirow{2}{*}{ Drawing } & SLI & 0.00 & 0.00 & 0.50 & \multirow{2}{*}{0.33} \\
\hline & Control & 0.00 & 0.00 & 0.50 & \\
\hline \multirow{2}{*}{ Looking at books } & SLI & 0.00 & 0.00 & 1.86 & \multirow{2}{*}{0.78} \\
\hline & Control & 0.00 & 0.00 & 2.00 & \\
\hline \multirow{2}{*}{ Playing table top games } & SLI & 0.00 & 0.00 & 0.00 & \multirow{2}{*}{0.50} \\
\hline & Control & 0.25 & 0.50 & 1.50 & \\
\hline \multirow{2}{*}{ Playing electric games } & SLI & 1.50 & 0.50 & 2.38 & \multirow{2}{*}{0.50} \\
\hline & Control & 0.50 & 0.00 & 2.00 & \\
\hline \multirow{2}{*}{ Listening to reading } & SLI & 0.50 & 0.00 & 1.88 & \multirow{2}{*}{0.57} \\
\hline & Control & 0.25 & 0.00 & 1.38 & \\
\hline \multirow{2}{*}{ Exercise at home indoors } & SLI & 0.00 & 0.00 & 0.38 & \multirow{2}{*}{0.94} \\
\hline & Control & 0.00 & 0.00 & 0.38 & \\
\hline \multirow{2}{*}{ Watching TV/video } & SLI & 3.50 & 2.62 & 4.38 & \multirow{2}{*}{0.94} \\
\hline & Control & 3.50 & 2.13 & 4.38 & \\
\hline \multirow{2}{*}{ Activity with music } & SLI & 0.00 & 0.00 & 0.00 & \multirow{2}{*}{0.79} \\
\hline & Control & 0.00 & 0.00 & 0.00 & \\
\hline \multirow{2}{*}{ Guided hobbies } & SLI & 0.00 & 0.00 & 1.00 & \multirow{2}{*}{0.31} \\
\hline & Control & 0.50 & 0.00 & 1.88 & \\
\hline \multirow{2}{*}{ Meal times } & SLI & 4.00 & 3.13 & 4.88 & \multirow{2}{*}{0.74} \\
\hline & Control & 4.50 & 3.00 & 5.00 & \\
\hline \multirow{2}{*}{ Washing, sauna } & SLI & 2.75 & 2.13 & 3.50 & \multirow{2}{*}{0.06} \\
\hline & Control & 2.50 & 1.63 & 2.50 & \\
\hline \multirow{2}{*}{ Doing homework } & SLI & 0.00 & 0.00 & 1.00 & \multirow{2}{*}{0.31} \\
\hline & Control & 0.00 & 0.00 & 0.88 & \\
\hline
\end{tabular}

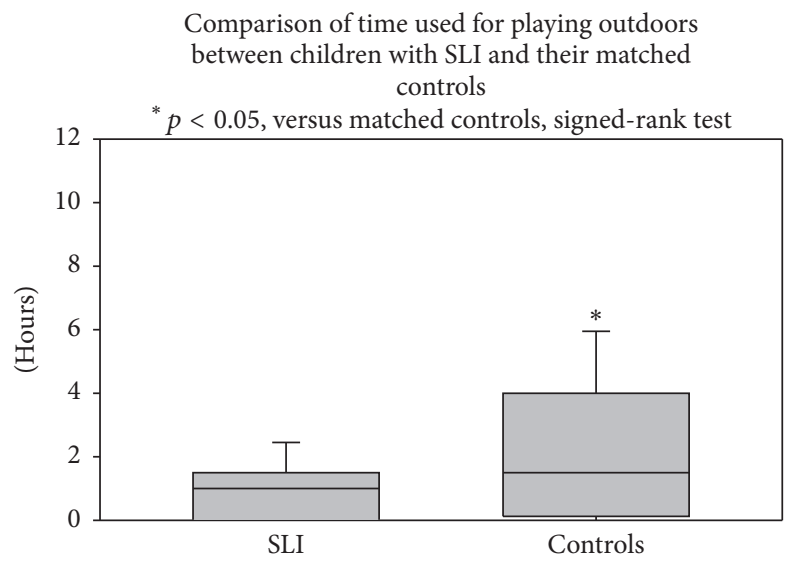

Figure 2: Playing outdoors. Median scores with 25\% and 75\% quartiles are presented as box plots. Brackets show the lowest $10 \%$ and the highest $90 \%$.

significantly more often than parents of control children (Figure 4).

\section{Discussion}

This first ever prospective study agrees with retrospective findings suggesting that children with SLI really may have

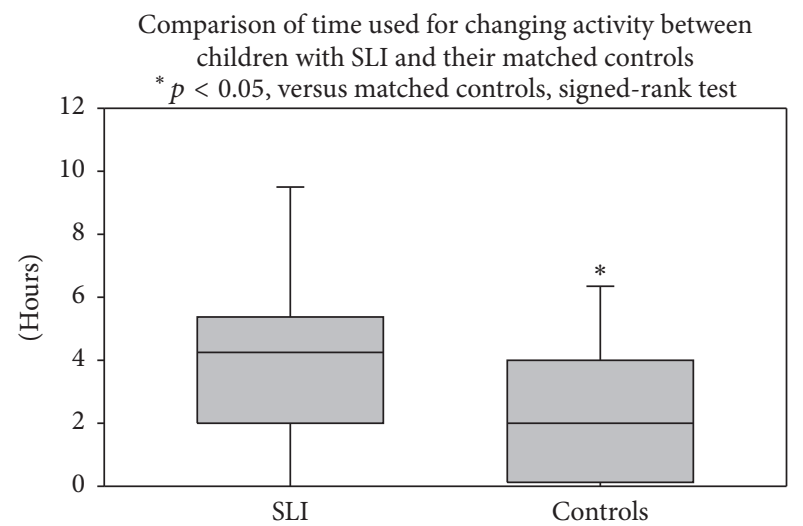

FIGURE 3: Changing activity. Median scores with $25 \%$ and $75 \%$ quartiles are presented as box plots. Brackets show the lowest $10 \%$ and the highest $90 \%$.

somewhat different daily activities than their healthy counterparts $[7,9,12,14]$. These differences appeared although number of our subjects was small. At home children with SLI seemed to have more situations when they do not concentrate on one activity at a time than their controls. Parents of children with SLI indicated this varying activity, lack of concentration, and running wild by reporting more activities of "changing activity." The difficulty of children with SLI to 


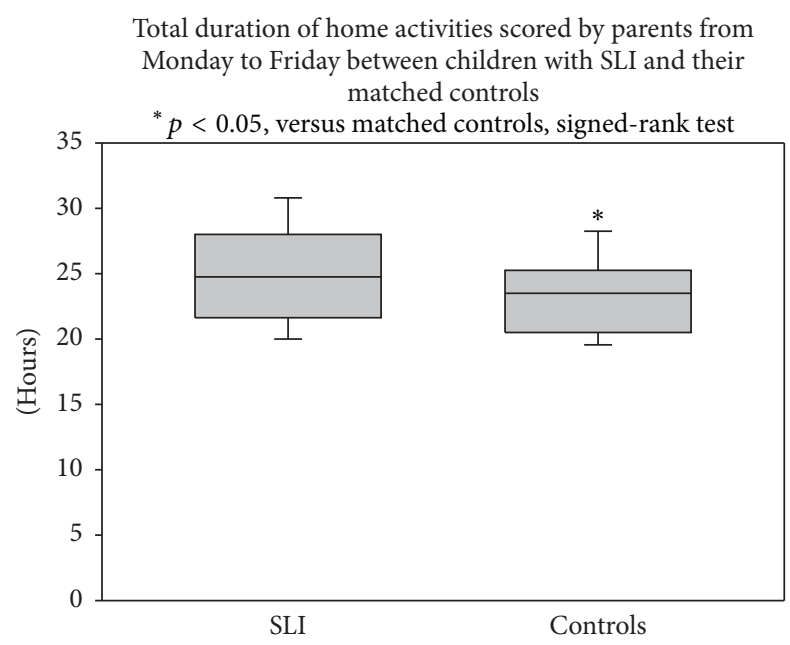

FIGURE 4: Parents overlapping choices. Median scores with 25\% and $75 \%$ quartiles are presented as box plots. Brackets show the lowest $10 \%$ and the highest $90 \%$.

maintain one activity may also be the explanation for parents of children with SLI scoring more overlapping choices than parents of control children. Parents of children with SLI also reported fewer activities of "playing outdoors" than parents of control children. Less time for playing outdoors may be a sign of problems in social pragmatic skills. Problems in social pragmatic skills of children with SLI have been found in earlier published studies, too [35-37]. Although the difference in "playing table top games" parameter failed to remain statistically significant after retesting the specificity, the trend to difference was analogous to "playing outdoors" parameter.

Yet, the observed differences were minor and these quantitative parameters do not help to understand the quality of interactions within the activities. Also parental input or collaborative or cooperative play with peers cannot be studied with the present data. It may not be the activity itself that is important compared with the nature of the interaction within the activity. Therefore it is difficult to draw clear conclusions what these differences reflect in context of SLI.

These data suggested that children with SLI spend more time in "changing activity" than their matched controls. In line with this, parents of children with SLI made more overlapping choices when scoring activity. These overlapping choices forced us to run specificity testing of the significant differences in the studied activities. The findings of these data also support the clinical experiences of SLTs, according to which parents have reported their children with SLI having problems in organizing their own behaviour in a coherent and consistent manner. Putative explanations for these phenomena are various. For example, age appropriate language abilities in all daily situations help children to plan and change the activity and thereby language impairments may cause difficulties in this planning and activity changing [36, 38]. As an alternative explanation, children with SLI have also been reported to have difficulties in recognizing the perspective and needs of other individuals [36]. They seem to fail frequently to provide adequate explanations to others regarding their behaviour thus indicating problems in executive functions $[36,38]$. Thirdly, it has been suggested that because of the difficulties in higher order thinking and reasoning skills children with SLI may have difficulties in analysing social situations, setting goals to resolve conflict and to initiate an interaction $[36,38]$. Though our data were small, all of the above mentioned difficulties might have appeared in daily living as moments when parents could not specify the activity of their child but chose the alternative of "changing activity" and made overlapping choices when scoring activity.

As discussed earlier, the behaviour of children with SLI is affected by functions that appear in complicated clusters [38]. Though SLI is an impairment in language the difficulties are not solely confined to the verbal behaviour but they extend to nonverbal behaviour, too [38]. The executive functioning difficulties of children with SLI have been discussed to show similar prevalence as of those of children with ADHD [38]. Also, the comorbidity of language impairments and other developmental disorders have been discussed through the decade [39]. The findings of the present small data support the earlier studies suggesting the nonspecific nature of SLI [3840]. Children with SLI indicated more varying activity and lack of concentration and this caused the bigger number of overlapping choices and "changing activity-scores" of parents of children with SLI than parents of their controls.

The present data found no statistically significant differences between the study groups of activities of looking at books, listening to reading, doing homework, or guided hobbies that may contribute the most to language learning. Neither were statistically significant differences found in screen time parameter. The effect of nature-nurture relationship on language development $[17,18]$ is well known and parents play a critical role in their children's language development, as they are the source of the genes and they modify the home environment of their children [41]. However, lack of differences in these daily activities hints that the putative differences, even if they actually would exist, seem not to be very prominent. Due to our small data further interpretation of this result is not performed.

\section{Strengths and Limitations}

The strength of the present study was the case-control setting and the prospective data collection daily during the same time period with all children. In addition, all children of this matched case-control study lived in the same town, at the same areas, thus having supposedly the same sort of social surroundings and similar facilities for their daily activities. The cultural background of the participants in the study was homogenous. Among the strengths of the present study were also the length of the study period, one week, and daily questionnaires that are supposed to diminish the mistakes of memorising.

The main weakness of this study was the small number of the participants. Partially this was due to our relatively small cohort $[30,31]$ and, thus, the number of case-control pairs 
remained small. This hampers possibilities to make clearcut conclusions about parameters which did not turn out to differ statistically significantly and allows only preliminary conclusions to be drawn from these parts of the data. Prospective studies with bigger data are required to answer the questions regarding whether there are differences in these parameters or not.

Another putative methodological weakness in the present study was the parents' subjective nature of the observations on children's behaviour. Many of the parents are aware of the commonly known recommendations concerning children's developmental activities. All this may have affected parents' scoring behaviour when filling in the questionnaires, for example, estimating the time used for "watching TV/video." However, even though some of the parents may have tried to stress the commonly recommended actions in their answers, there is no reason to believe that this would have induced a group effect modifying the result.

We also had limited access to the diagnostic data of the children with SLI because the diagnoses were made in specialist health care. Full access to the data would have allowed us to review the nature and severity of each child with SLI more profoundly. Though listed activities were collected in the pilot study openly formulated descriptive data of activities might have given more information of the putative differences of daily activities between the children with SLI and their matched controls.

The majority of previous studies on human interactions at home rely on one-shot self-reported data and reports over extended periods of time are carried out as follow-ups by filling in questionnaires or interviewing parents retrospectively $[8,10]$. Studies using daily reports are not common in the field of SLI studies. Thus, home support for language learning has no standard forms of parent reports and, for example, frequency of book reading has been mostly studied by interviewing parents or asking questions about the frequency of reading $[9,10]$. Though language and communicative behaviour are learned at home, the studies in this area are difficult to carry out, because the method itself may cause changes in the targeted activities. The method of the present study, prospective parent reports, can be seen as reliable as the method used in published studies $[9,10,27,28]$.

\section{Conclusions}

The result of the present study suggests smaller differences and bigger similarities in duration of daily activities between children with SLI and their matched controls. The challenge for the future is to evaluate how relevant these differences and similarities in home activities are, especially for the intervention.

\section{Appendix}

\section{Daily Home Activities Questionnaire}

Day 1

Playing outdoors

口 Time 17-17.30 $\square$ Time 17.30-18.00

口 Time 18.00-18.30

口 Time 18.30-19.00

口 Time 19.00-19.30

口 Time 19.30-20.00

$\square$ Time 20.00-20.30

口 Time 20.30-21.00

$\square$ Time 21-

Playing indoors

$\square$ Time 17-17.30

口 Time 17.30-18.00

$\square$ Time $18.00-18.30$

口 Time 18.30-19.00

口 Time 19.00-19.30

$\square$ Time 19.30-20.00

$\square$ Time 20.00-20.30

$\square$ Time $20.30-21.00$

$\square$ Time 21-

Building

$\square$ Time 17-17.30

口 Time 17.30-18.00

口 Time 18.00-18.30

口 Time 18.30-19.00

口 Time 19.00-19.30

口 Time 19.30-20.00

$\square$ Time 20.00-20.30

口 Time 20.30-21.00

$\square$ Time 21-

Drawing
口 Time 17-17.30
$\square$ Time 17.30-18.00
$\square$ Time 18.00-18.30
口 Time 18.30-19.00
口 Time 19.00-19.30
口 Time 19.30-20.00
口 Time 20.00-20.30
$\square$ Time 20.30-21.00
$\square$ Time 21-

Looking at books
$\square$ Time 17-17.30
口 Time 17.30-18.00
$\square$ Time 18.00-18.30
口 Time 18.30-19.00
$\square$ Time 19.00-19.30
口 Time 19.30-20.00
口 Time 20.00-20.30
$\checkmark$ Time 20.30-21.00 
$\square$ Time 21-

Playing table top games

$\square$ Time 17-17.30

口 Time 17.30-18.00

$\square$ Time 18.00-18.30

$\square$ Time 18.30-19.00

$\square$ Time 19.00-19.30

$\square$ Time 19.30-20.00

$\square$ Time 20.00-20.30

$\square$ Time 20.30-21.00

$\square$ Time 21-

Playing electric games

$\square$ Time 17-17.30

$\square$ Time 17.30-18.00

$\square$ Time 18.00-18.30

$\square$ Time 18.30-19.00

$\square$ Time 19.00-19.30

$\square$ Time 19.30-20.00

$\square$ Time 20.00-20.30

$\square$ Time 20.30-21.00

$\square$ Time 21-

Listening to reading

$\square$ Time 17-17.30

$\square$ Time 17.30-18.00

$\square$ Time 18.00-18.30

$\square$ Time 18.30-19.00

$\square$ Time 19.00-19.30

$\square$ Time 19.30-20.00

$\square$ Time 20.00-20.30

$\square$ Time 20.30-21.00

$\square$ Time 21-

Exercise at home indoors

$\square$ Time 17-17.30

$\checkmark$ Time 17.30-18.00

$\square$ Time 18.00-18.30

$\square$ Time 18.30-19.00

$\square$ Time 19.00-19.30

$\square$ Time 19.30-20.00

$\square$ Time 20.00-20.30

$\square$ Time 20.30-21.00

$\square$ Time 21-

Watching TV/video

$\square$ Time 17-17.30

$\square$ Time 17.30-18.00

$\square$ Time 18.00-18.30

$\square$ Time 18.30-19.00

$\square$ Time 19.00-19.30 $\square$ Time 19.30-20.00

$\square$ Time 20.00-20.30

$\square$ Time 20.30-21.00

$\square$ Time 21-

Activities with music

$\square$ Time 17-17.30

$\square$ Time 17.30-18.00

$\square$ Time 18.00-18.30

$\square$ Time 18.30-19.00

$\square$ Time 19.00-19.30

$\square$ Time 19.30-20.00

$\square$ Time 20.00-20.30

$\square$ Time 20.30-21.00

$\square$ Time 21-

Guided hobbies

口 Time 17-17.30

$\square$ Time 17.30-18.00

$\square$ Time 18.00-18.30

$\square$ Time 18.30-19.00

$\square$ Time 19.00-19.30

$\square$ Time 19.30-20.00

$\square$ Time 20.00-20.30

$\square$ Time 20.30-21.00

$\square$ Time 21-

Meal times

$\square$ Time 17-17.30

$\square$ Time 17.30-18.00

口 Time 18.00-18.30

$\square$ Time 18.30-19.00

$\square$ Time 19.00-19.30

$\square$ Time 19.30-20.00

口 Time 20.00-20.30

$\square$ Time 20.30-21.00

$\square$ Time 21-

Washing, sauna

$\square$ Time 17-17.30

$\square$ Time 17.30-18.00

口 Time 18.00-18.30

$\square$ Time 18.30-19.00

$\square$ Time 19.00-19.30

$\square$ Time 19.30-20.00

$\square$ Time 20.00-20.30

$\square$ Time 20.30-21.00

$\square$ Time 21-

Changing activity

$\square$ Time 17-17.30

$\square$ Time 17.30-18.00 
$\square$ Time 18.00-18.30

$\square$ Time 18.30-19.00

$\square$ Time 19.00-19.30

$\square$ Time 19.30-20.00

$\square$ Time 20.00-20.30

$\square$ Time 20.30-21.00

$\square$ Time 21-

Doing homework

$$
\begin{aligned}
& \square \text { Time } 17-17.30 \\
& \square \text { Time 17.30-18.00 } \\
& \square \text { Time 18.00-18.30 } \\
& \square \text { Time 18.30-19.00 } \\
& \square \text { Time 19.00-19.30 } \\
& \square \text { Time 19.30-20.00 } \\
& \square \text { Time 20.00-20.30 } \\
& \square \text { Time 20.30-21.00 } \\
& \square \text { Time 21- }
\end{aligned}
$$

\section{Competing Interests}

The authors declare that there is no conflict of interests.

\section{Acknowledgments}

This study is a part of the research project SLI in Vantaa studying the etiology, status, and prognosis of SLI. Public health nurses Minna Haanpää and Aino Rista acted as research nurses. Paediatrician Leena Isotalo and Ph.D., SLT Pia Isoaho had useful discussions about the nature of SLI with the authors. Network of Academic Health Centres HUCH provided general support and important discussions. Special thanks are due to the children and their parents who participated in this study. This study was supported by a special governmental subsidy for health sciences research (ERVA).

\section{References}

[1] International Classification of Diseases, http://apps.who.int/ classifications/icd10/browse/2015/en\#/F80-F89.

[2] H. Van Balkom, L. Verhoeven, and M. Van Weerdenburg, "Conversational behaviour of children with developmental language delay and their caretakers," International Journal of Language and Communication Disorders, vol. 45, no. 3, pp. 295-319, 2010.

[3] C. S. Hammer, J. B. Tomblin, X. Zhang, and A. L. Weiss, "Relationship between parenting behaviours and specific language impairment in children," International Journal of Language and Communication Disorders, vol. 36, no. 2, pp. 185-205, 2001.

[4] M. L. Rice, “Toward epigenetic and gene regulation models of specific language impairment: looking for links among growth, genes, and impairments," Journal of Neurodevelopmental Disorders, vol. 4, no. 1, pp. 1-14, 2012.

[5] J. Law, J. B. Tomblin, and X. Zhang, "Characterizing the growth trajectories of language-impaired children between 7 and 11 years of age," Journal of Speech, Language, and Hearing Research, vol. 51, no. 3, pp. 739-749, 2008.
[6] L. M. Justice, L. E. Skibbe, A. S. McGinty, S. B. Piasta, and S. Petrill, "Feasibility, efficacy, and social validity of homebased storybook reading intervention for children with language impairment," Journal of Speech, Language, and Hearing Research, vol. 54, no. 2, pp. 523-538, 2011.

[7] C. S. Hammer, G. Farkas, and S. Maczuga, "The language and literacy development of head start children: a study using the family and child experiences survey database," Language, Speech, and Hearing Services in Schools, vol. 41, no. 1, pp. 70-83, 2010.

[8] A. S. McGinty and L. M. Justice, "Predictors of print knowledge in children with specific language impairment: experiential and developmental factors," Journal of Speech, Language, \& Hearing Research, vol. 52, no. 1, pp. 81-97, 2009.

[9] I. Schoon, S. Parsons, R. Rush, and J. Law, "Childhood language skills and adult literacy: a 29-year follow-up study," Pediatrics, vol. 125, no. 3, pp. e459-e466, 2010.

[10] D. Boudreau, "Use of a parent questionnaire in emergent and early literacy assessment of preschool children," Language, Speech, and Hearing Services in Schools, vol. 36, no. 1, pp. 33-47, 2005.

[11] M. D. Malani, A. Barina, K. Kludjian, J. Perkowski, C. Nye, and J. Schwartz, "Added value of dialogic book reading for young children's vocabulary development," Evidence-Based Communication Assessment and Intervention, vol. 4, no. 4, pp. 178-182, 2010.

[12] P. S. Tandon, C. Zhou, P. Lozano, and D. A. Christakis, "Preschoolers' total daily screen time at home and by type of child care," The Journal of Pediatrics, vol. 158, no. 2, pp. 297-300, 2011.

[13] W. Chonchaiya and C. Pruksananonda, "Television viewing associates with delayed language development," Acta Paediatrica, vol. 97, no. 7, pp. 977-982, 2008.

[14] F. J. Zimmerman and D. A. Christakis, "Children's television viewing and cognitive outcomes: a longitudinal analysis of national data," Archives of Pediatrics and Adolescent Medicine, vol. 159, no. 7, pp. 619-625, 2005.

[15] M. Tanimura, K. Okuma, and K. Kyoshima, "Television viewing, reduced parental uterance, and delayed speech development in infants and young children," Archives of Pediatrics and Adolescent Medicine, vol. 161, pp. 618-619, 2007.

[16] American Academy of Pediatrics and Committee on Public Education, "American academy of pediatrics: children, adolescents, and television," Pediatrics, vol. 107, no. 2, pp. 423-426, 2001.

[17] J. J. Woods, M. J. Wilcox, M. Friedman, and T. Murch, "Collaborative consultation in natural environments: strategies to enhance family-centered supports and services," Language, Speech, and Hearing Services in Schools, vol. 42, no. 3, pp. 379392, 2011.

[18] U. Bronfenbrenner and S. J. Ceci, "Nature-nurture reconceptualized in developmental perspective: a bioecological model," Psychological Review, vol. 101, no. 4, pp. 568-586, 1994.

[19] J. Allen and C. R. Marshall, "Parent-Child Interaction Therapy (PCIT) in school-aged children with specific language impairment," International Journal of Language and Communication Disorders, vol. 46, no. 4, pp. 397-410, 2011.

[20] J. Baxendale and A. Hesketh, "Comparison of the effectiveness of the Hanen Parent Programme and traditional clinic therapy," International Journal of Language and Communication Disorders, vol. 38, no. 4, pp. 397-415, 2003.

[21] A. Buschmann, B. Jooss, A. Rupp, F. Feldhusen, J. Pietz, and H. Philippi, "Parent based language intervention for 2-year-old 
children with specific expressive language delay: a randomised controlled trial," Archives of Disease in Childhood, vol. 94, no. 2, pp. 110-116, 2009.

[22] World Health Organization, International Classification of Functioning, Disability and Health (ICF), WHO, Geneva, Switzerland, 2001.

[23] S. E. Anderson, C. D. Economos, and A. Must, "Active play and screen time in US children aged 4 to 11 years in relation to sociodemographic and weight status characteristics: a nationally representative cross-sectional analysis," BMC Public Health, vol. 8, article 366, 2008.

[24] J.-A. Prendeville, P. A. Prelock, and G. Unwin, "Peer play interventions to support the social competence of children with autism spectrum disorders," Seminars in Speech and Language, vol. 27, no. 1, pp. 32-46, 2006.

[25] M. Joffe, J. Key, N. Best, N. Keiding, T. Scheike, and T. K. Jensen, "Studying time to pregnancy by use of a retrospective design," American Journal of Epidemiology, vol. 162, no. 2, pp. 115-124, 2005.

[26] K. E. Diamond and J. Squires, "The role of parental report in the screening and assessment of young children," Journal of Early Intervention, vol. 17, no. 2, pp. 107-115, 1993.

[27] D. Bricker, J. Squires, R. Kaminski, and L. Mounts, "The validity, reliability, and cost of a parent-completed questionnaire system to evaluate at-risk infants," Journal of Pediatric Psychology, vol. 13, no. 1, pp. 55-68, 1988.

[28] H. M. Feldman, P. S. Dale, T. F. Campbell et al., "Concurrent and predictive validity of parent reports of child language at ages 2 and 3 years," Child Development, vol. 76, no. 4, pp. 856-868, 2005.

[29] S. Hannus, T. Kauppila, and K. Launonen, "Increasing prevalence of specific language impairment (SLI) in primary health care of a Finnish town, 1989-1999," International Journal of Language \& Communication Disorders, vol. 44, pp. 79-97, 2009.

[30] S. Hannus, T. Kauppila, J. Pitkäniemi, and K. Launonen, "Use of language tests when identifying specific language impairment in primary health care," Folia Phoniatrica et Logopaedica, vol. 65, no. 1, pp. 40-46, 2013.

[31] P. Isoaho, T. Kauppila, and K. Launonen, "Specific language impairment (SLI) and reading development in early school years," Child Language Teaching and Therapy, vol. 1, pp. 1-11, 2015.

[32] V. Kaupunki, Tilasto ja tutkimus, B9:2006, Vantaan väestö 2005/2006, (Town of Vantaa, Research and Statistics, B9:2006), http://www.vantaa.fi/tilastot.

[33] D. M. Hartung and D. Touchette, "Overview of clinical research design," American Journal of Health-System Pharmacy, vol. 66, no. 4, pp. 398-408, 2009.

[34] J. C. Anderson and D. W. Gerbing, "Structural equation modeling in practice: a review and recommended two-step approach," Psychological Bulletin, vol. 103, no. 3, pp. 411-423, 1988.

[35] A. C. Jerome, M. Fujiki, B. Brinton, and S. L. James, "Selfesteem in children with specific language impairment," Journal of Speech, Language, and Hearing Research, vol. 45, no. 4, pp. 700-714, 2002.

[36] K. Marton, B. Abramoff, and S. Rosenzweig, "Social cognition and language in children with specific language impairment (SLI)," Journal of Communication Disorders, vol. 38, no. 2, pp. 143-162, 2005.

[37] D. V. Bishop, J. Chan, C. Adams, J. Hartley, and F. Weir, "Conversational responsiveness in SLI. Evidence of disproportionate pragmatic difficulties in a subset of children," Journal of Psychopathology, vol. 12, no. 2, pp. 177-199, 2000.

[38] L. A. Henry, D. J. Messer, and G. Nash, "Executive functioning in children with specific language impairment," Journal of Child Psychology and Psychiatry and Allied Disciplines, vol. 53, no. 1, pp. 37-45, 2012.

[39] E. L. Hill, "Non-specific nature of specific language impairment: a review of the literature with regard to concomitant motor impairments," International Journal of Language and Communication Disorders, vol. 36, no. 2, pp. 149-171, 2001.

[40] C. A. Liiva and P. L. Cleave, "Roles of initiation and responsiveness in access and participation for children with specific language impairment," Journal of Speech, Language \& Hearing Research, vol. 48, pp. 868-883, 2005.

[41] M. L. Rice, "Toward epigenetic and gene regulation models of specific language impairment: looking for links among growth, genes, and impairments," Journal of Neurodevelopmental Disorders, vol. 4, no. 1, article 27, 2012. 


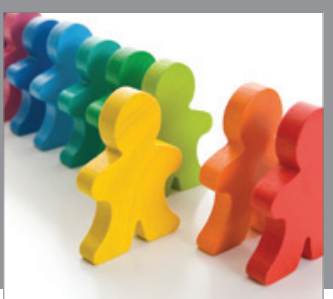

Autism

Research and Treatment
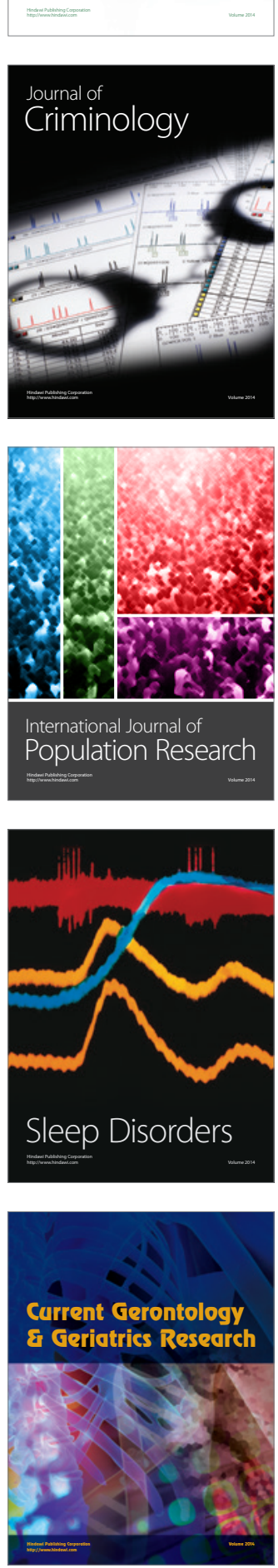

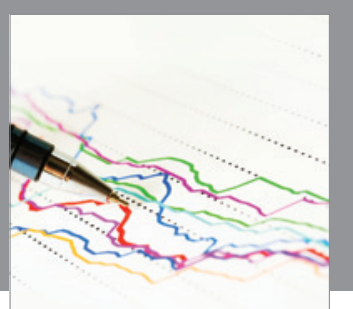

Economics

Research International
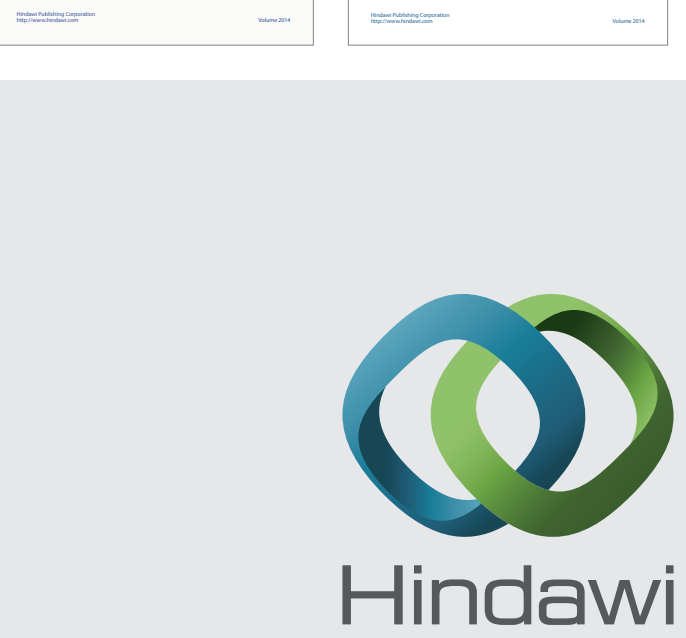

Submit your manuscripts at

http://www.hindawi.com
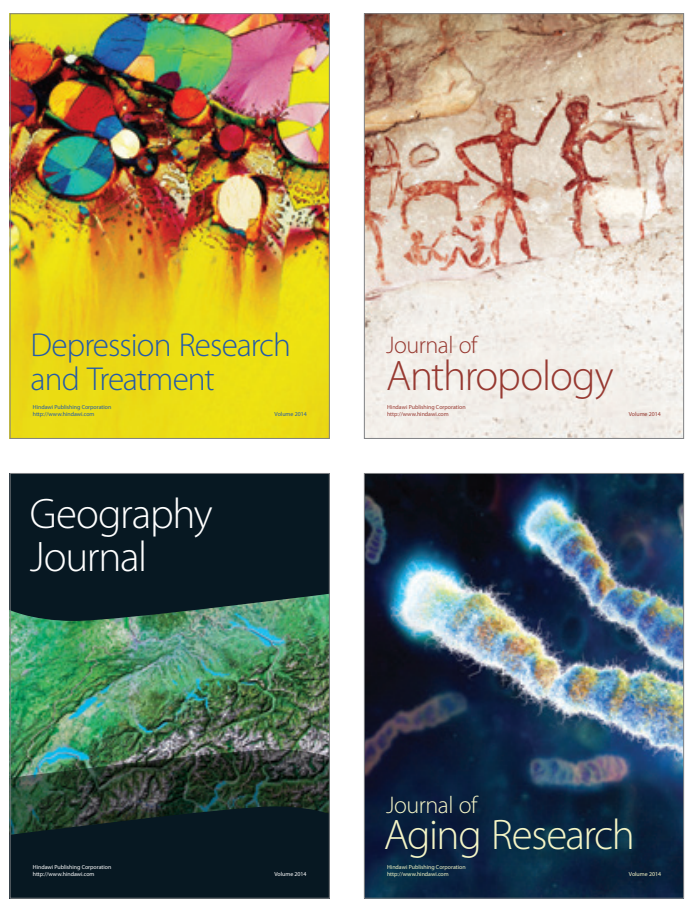
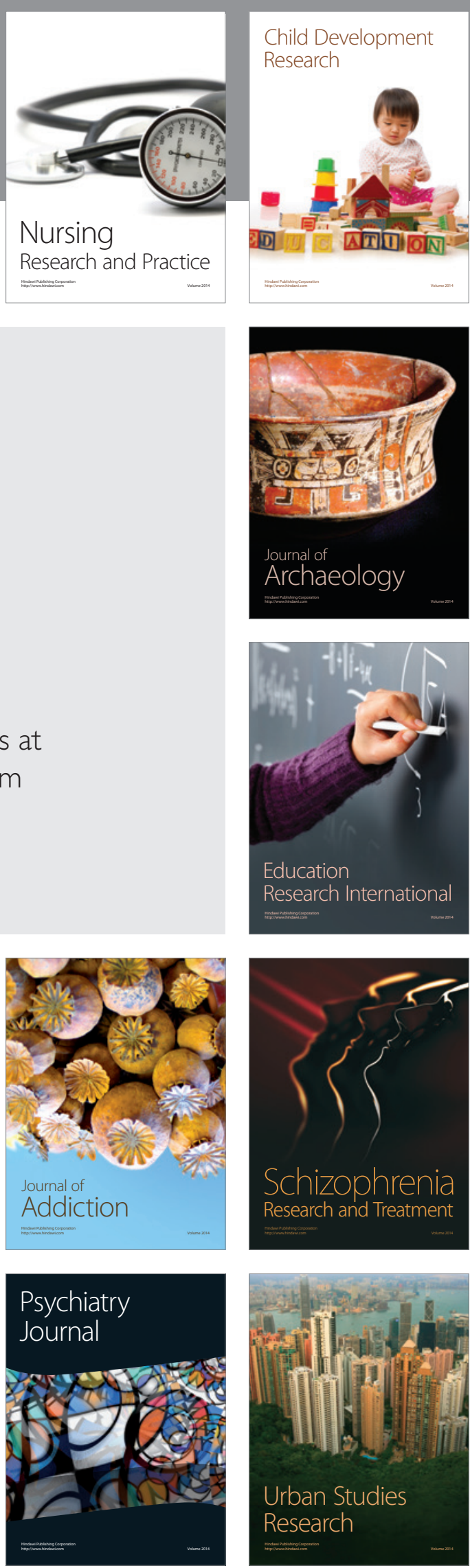